\title{
PENGARUH DISIPLIN KERJA DAN PUNISHMENT TERHADAP PRODUKTIVITAS KERJA PEGAWAI CV MITRA TUNAS MANDIRI (MTM) DI BANDAR LAMPUNG
}

\author{
Trisnowati Josiah ${ }^{(1)}$, Ali Usman ${ }^{(2)}$ \\ Fakultas Ekonomi Universitas Sang Bumi Ruwa Jurai \\ trisnowati.josiah@fe.saburai.ac.id,ali_usman@gmail.com
}

\begin{abstract}
Abstrak.Disiplin Kerja dan Punishment merupakan sistem pengawasan ketat yang penting dilaksanakan untuk menunjang Produktivitas Kerja Pegawai sekaligus memberi sanksi bagi yang kurang disiplin bekerja. Disiplin Kerja dan Punishment dapat mempengaruhi Produktivitas Kerja Pegawai. Disiplin Kerja dan Punishment pada karyawan bertujuan untuk meningkatkan Produktivitas Kerja Pegawai sehingga seorang karyawan akan maksimal dalam bekerja. Penelitian ini merupakan penelitian kuantitatif yang bertujuan untuk menganalisa pengaruh disiplin Kerja dan Punishment terhadap Produktivitas Kerja Pegawai pada CV Mitra Tunas Mandiri. Populasi dalam penelitian ini adalah seluruh karyawan CV Mitra Tunas Mandiri yang berjumlah 73 orang. Teknik pengambilan sampel dalam penelitian ini menggunakan metode total sampling yakni mengambil seluruh anggota populasi menjadi sampel penelitian, sehingga ada 73 sampel penelitian. Metode pengumpulan data menggunakan kuesioner dan analisis data menggunakan regresi linier berganda. Hasil penelitian memperlihatkan bahwa Disiplin Kerja dan Punishment berpengaruh terhadap Produktivitas Kerja Pegawai pada CV Mitra Tunas Mandiri Bandar Lampung.
\end{abstract}

Kata kunci:Disiplin Kerja, Punishment, dan Produktivitas Kerja

\section{PENDAHULUAN}

Sumber daya manusia merupakan bagian penggerak dari perusahaan yang memiliki potensi berkembang dan secara aktif mendorong produktifitas dalam memenuhi tujuan perusahaan. Malayu Hasibuan (2003) menjelaskan manajemen sumber daya manusia adalah ilmu dan seni yang mengatur hubungan dan peranan tenaga kerja, agar efektif dan efisien membantu terujudnya tujuan. Dewasa ini peran manajemen sumber daya manusia dalam perusahaan telah mendapat perhatian penting dari sebagian akademis. Terutama dalam era globalisasi saat ini telah disadari bahwa pengelolaan sumber daya manusia merupakan salah satu kunci sukses dan keberhasilan dalam suatu perusahaan. Pada dasarnya sumber daya manusia merupakan sumber daya yang berbeda dari sumber daya-sumber daya yang ada dalam perusahaan seperti sumber daya alam dan sumber daya modal. Dapat dijelaskan bahwa pengelolaan sumber daya manusia tidaklah mudah, sebab masing-masing manusia memiliki unsur-unsur berbeda seperti latar belakang, cara pandang, pemikiran, sifat, selera, dan masih banyak unsur lainnya. Berdasarkan unsur-unsur inilah tercermin pola tingkah laku manusia dalam kehidupan sehari-hari. Seiring dengan perkembangan zaman, unsur-unsur yang berbeda dalam setiap kehidupan manusia tersebut secara umum akan senantiasa berkembang dan berubah-ubah. .

Perusahaan juga membutuhkan sumber daya manusia yaitu para karyawan. Karyawan merupakan sumber daya yang penting bagi perusahaan karena memiliki bakat, tenaga dan kretifitas yang sangat dibutuhkan oleh perusahaan untuk 
mencapai tujuannya, kinerja yang dicari oleh perusahaan adalah seseorang yang tergantung dari kemampuan, motivasi dan dukungan individu yang diterima (Mathis and Jakson, 2002; 89). Sumber daya manusia merupakan tokoh sentral dalam organisasi maupun perusahaan. Perusahaan yang baik, tumbuh dan berkembang akan menitik beratkan pada sumber daya manusia (human resources) guna menjalankan fungsinya sehingga kemampuan teknis, teoritis, konseptual, moral dari para pelaku organisasi disemua level pekerjaan sangat dibutuhkan. Diketahui juga bahwa pada dasarnya hubungan antara perusahaan dan karyawan adalah hubungan yang saling menguntungkan. Di satu sisi perusahaan ingin mendapatkan keuntungan yang besar, sementara di sisi lain karyawan membutuhkan harapan dan kebutuhan tertentu yang harus dipenuhi perusahaan. Dengan demikian perusahaan dan karyawan memiliki keterikatan hubungan dan selalu dihadapkan pada permasalahanpermasalahan.

CV. Mitra Tunas Mandiri Bandar Lampung adalah perusahaan yang bergerak di bidang jasa pengurusan export import via Pelabuhan Panjang. CV. Mitra Tunas Mandiri Bandar Lampung terletak di jalan selat malaka 1 No. 5 KP. Teluk Harapan Kelurahan Panjang Selatan Kecamatan Panjang Bandar Lampung. No Telpon 0721-340-0187. Para karyawan CV. Mitra Tunas Mandiri Bandar Lampung banyak menghadapi permasalahan mengenai pekerjaannya, baik permasalahan yang bersifat eksternal maupun persoalan yang bersifat internal yang membuat produktivitas kerja karyawan menurun. Salah satu contoh kasus eksternal yang dialami pihak CV. Mitra Tunas Mandiri Bandar Lampung yaitu keterlambatan pengiriman. Timbulnya masalah tersebut juga disebabkan oleh persoalan internal. Salah satu contoh permasalahan internal yang dihadapai oleh CV. Mitra Tunas Mandiri Bandar Lampung adalah persoalan sumber daya manusia yang memiliki budaya kerja dan profesionalisme masih rendah, mekanisme kerja antara pimpinana dan karyawan yang kurang instensif sehingga perlu ditingkatkan, karyawan baru yang mendapatkan training atau pelatihan dan teori mengenai pekerjaannya hanya dalam waktu seminggu yang dirasa karyawan sangat kurang maksimal,serta karyawan memiliki beban kerja yang sangat tinggi dalam hal perhitungan selisih keuangan perusahaan.

Terkait dengan hal tersebut, dirasa sangat penting bagi CV. Mitra Tunas Mandiri Bandar Lampung untuk melakukan pengelolaan sumber daya manusia dalam suatu perusahaan yang memegang peranan penting dalam upaya peningkatan prestasi suatu lembaga. Keberhasilan suatu perusahaan bukan tergantung pada kuantitas melainkan kualitas karyawan yang professional dan mampu mengembangkan usaha. Produktivitas kerja karyawan dapat dicapai melalui pengelolaan SDM yang terencana, terarah, dan terpadu sesuai ketentuan dan perkembangan perusahaan. Hal ini juga dapat didukung oleh disiplin kerjadan punishment, bagi karyawan CV. Mitra Tunas Mandiri Bandar Lampung sehinggan tujuan dan cita-cita perusahaan dapat tercapai dan terpenuhi di masa depan.

Berdasarkan permasalahan diatas, maka peneliti mengambil judul "Pengaruh

Disiplin Kerja dan Punishment Terhadap Produktivitas Kerja Karyawan pada CV. Mitra Tunas Mandiri (MTM) Bandar Lampung”.

\section{KAJIAN TEORI}

\section{Pengertian Disiplin Kerja}


Manusia yang sukses adalah
manusia yang mampu mengatur
danmengendalikan diri yang menyangkut
pengaturan cara hidup dan mengaturcara kerja. Maka erat hubungannya antara manusia sukses dengan pribadidisiplin. Berkaitan dengan disiplin itu sendiri para ahli memiliki bermacammacampemaknaan seperti yang diungkapkan oleh Martoyo (2000: 151) disiplin itu berasal dari bahasa Latin dari kata "discipline" yang berarti latihan atau pendidikan kesopanan dankerohanian serta pengembangan tabiat.

Hasibuan (2006: 135), dijabarkan bahwasanya disiplin adalah sikap kejiwaan dari seseorang atau sekelompok orang yang senantiasa berkehendak untuk mengikuti/mematuhi segala aturan yang telah ditetapkan. Disiplin juga berarti latihan yang mengembangkan pengendalian diri, watak atau ketertiban dan efisiensi; kepatuhan atau ketaatan terhadap ketentuan dan peraturan pemerintah atau etik, norma dan kaidah yang berlaku dalam masyarakat (Sinungan, 2006: 145-146).

$\begin{array}{llr}\text { Disiplin } & \text { merupakan } \\ \text { kesadaran dan kesediaan } & \text { seserang }\end{array}$ mentaati semua peraturan perushaan yang dibuat manajemen yang mengingat anggota perusahaan agar dapat dijalankan semua karyawan baik dengan kesadaran sedniri maupun dengan paksaan. Dari beberapa pengertian disiplin kerja yang dikemukakan oleh beberapa ahli dapat disimpulkan bahwa disiplin kerja adalah sikap kesadaran,kerelaan dan kesedian seseorang dalam mematuhi dan menaati peraturan dan norma - norma sosial yang berlaku di lingkungan sekitarnya.

Menurut Singodimenjo dalam Sutrisno (2011:86) bahwa hal yang mempengaruhi disiplin pegawai adalah:

1. Besar kecilnya pemberian kompensasi Besar kecilnya kompensasi dapat mempengaruhi tegaknya disiplin.Para karyawan akan mematuhi segala peraturan yang berlaku, bila ia merasa mendapat jaminan balas jasa yang setimpal dengan jerih payahnya yang telah dikontribusikannya bagi perusahaan.

2. Ada tidaknya keteladanan pimpinan dalam perusahaan Keteladanan pimpinan sangat penting sekali, karena dalam lingkunganperusahaan, semua karyawan akan selalu memperhatikan bagaimanapimpinan dapat menegakkan disiplin dirinya dan bagaimana ia dapatmengendalikan dirinya sendiri ucapan, perbuatan, dan sikap yang dapat merugikan aturan disiplin yang sudah ditetapkan.

3. Ada tidaknya aturan pasti yang dapat dijadikan peganganPembinaan disiplin tidak akan dapat terlaksana dalam perusahaan, bila tidak ada aturan tertulis yang pastiuntuk dapat dijadikan pegangan bersama.

4. Keberanian pimpinan dalam mengambil tindakan bila ada seseorang karyawan yang melanggar disiplin, maka perlu ada keberanian pimpinan untuk mengambil tindakan yang sesuai dengan pelanggaran yang dibuatnya.

Tindakan pendisiplinan kepada pegawai haruslah sama pemberlakuaanya. Disini tindakan disiplin berlaku bagi semua, tidak memilih, memilah dan memihak kepada siapapun yang melanggar akan dikenakan sanksi pendisiplinan yang sama termasuk bagi manajer atau pimpinan, karena pimpinan harus memberi contoh terhadap para bawahannya.

\section{Pengertian Punishment}

Sanksi atau punishment adalah hukuman yang diberikan karena adanya pelanggaran terhadap yang berlaku. Punishment adalah penderitaan yang diberikan atau ditimbulkan dengan sengaja oleh seseorang sesudah terjadi suatu 
pelanggaran, kejahatan, atau kesalahan (Purwanto, 2007:186).

Sanksi atau punishment dapat diberikan berupa teguran, surat peringatan, skrorsing dan bahkan pemberhentian atau pemutusan hubungan kerja. Karyawan yang mendapatkan sanksi atau hukuman biasanya tidak mendapatkan bonus pada bulan terkait. Atau bahkan tidak bisa mendapatkan kesempatan promosi jabatan apabila kesalahan yang di lakukan cukup berat.

Menurut Sondang P. Siagian dalam Ella Sari (2015) memberikan hukuman terhadap tersebut sebagai berikut :

a. Peringatan Lisan

b. Perinagatan tertulis ketidakpuasaan oleh atasan langsung

c. Penundaan kenaikan gaji berkala

d. Penundaan kenaikan pangkat

e. Pembebasan dari jabatan

f. Pemberhentian sementara

g. Pemberhentian atas permintaan sendiri

h. Pemberhentian dengan hormat tidak atas mintaan sendiri.

Punishment (hukuman) adalah tindakan pendidik yang sengaja dan secara sadar diberikan kepada anak didik yang melakukan suatu kesalahan, agar anak didik tersebut menyadari kesalahannya dan berjanji dalam hatinya untuk tidak mengualnginya.

Jenis - jenis Punishment Menurut Rivai (2005) jenis - jenis Punishment sebagai berikut :

1. Hukuman ringan

a. Teguran lisan kepada karyawan yang bersangkutan

b. Teguran tertulis

c. Pernyataan tidak puas secara tertulis

2. Hukuman sedang

a. Penundaan kenaikan gaji yang sebelumnya telah direncanakan sebagaimana karyawan lainnya b. Penururunan gaji yang besarnya disesuaikan dengan peraturan peraturan

c. Penundaan kenakan pangkat atau promosi

3. Hukuman Berat

a. Penurunan pangkat

b. Pembebasan dari jabatan

c. Pemberhentian kerja atas permintaan karyawan yang bersangkutan

d. Pemutusan hubungan kerja sebagai karyawan perusahaan

\section{Produktivitas Kerja}

$$
\text { Menurut Wibowo (2011:109) }
$$
produktivitas adalah hubungan antara keluaran atau hasil organisasi dengan masukan yang diperlukan. Sunyoto (2012:202) mendefinisikan "produktivitas kerja adalah ukuran yang menunjukkan pertimbangan antara input dan output yang dikeluarkan perusahaan serta peran tenaga kerja yang dimiliki persatuan waktu”.

Menurut Ambar Teguh Sulistiyani dan Rosidah, mengatakan bahwa ada beberapa faktor yang menentukan besar kecilnya produktivitas, antara lain :
a. Knowledge
b. Skills
c. Abilities
d. Attitude
e. Behaviors

\section{METODE PENELITIAN}

\section{Objek Penelitian}

Objek penelitian merupakan permasalahan yang diteliti. Dalam penulisan skripsi ini, yang menjadi objek penelitian ini Disiplin Kerja, Punishment dan Produktivitas Kerja Pegawai. Objek penelitian yang menjadi variabel bebas atau 
independent variable adalah Disiplin Kerja(X1) dan Punishment(X2) kemudian variable terikat atau dependent variable adalah Produktivitas Kerja Pegawai (Y). Penelitian ini dilaksanakan di CV Mitra Tunas Mandiri Bandar Lampung.

\section{Metode Penelitian}

Jenis penelitian Deskriptif yaitu penelitian yang bertujuan untuk mengetahui pengaruh ataupun hubungan antara dua variabel atau lebih (Sugiyono, 2014). Pada penelitian saat ini yang dilihat pada rumusan masalah dan tujuan yang telah dikemukakan, maka penelitian ini termasuk penelitian asosiatif dengan pendekatan penelitian kuantitatif.

\section{Metode dan Teknik Pengumpulan Data}

Dalam penelitian ini jenis data yang diperlukan adalah:

a. Data Primer

Data primer adalah data asli yang dikumpulkan oleh penelitian untuk data hasil jawaban, menjawab masalah risetnya secara khusus. Jenis data yang digunakan adalah jawaban kuisioner yang dibagikan kepada karyawan CV. Mitra Tunas Mandiri (MTM) Bandar Lampung.

\section{b. Data Sekunder}

Data sekunder adalah data yang telah dikumpulkan oleh pihak lain bukan oleh peneliti sendiri dengan tujuan yang lain, yaitu data yang diperoleh oleh pihak kedua. Data sekunder dalam penelitian ini adalah data karyawan, data Disiplin Kerja, Punishment dan data Produktivitas Kerja cara wawancara dengan pihak karyawan CV. Mitra Tunas Mandiri (MTM) Bandar Lampung.

Teknik pengumpulan data/informasi yang dilakukan dalam penelitian ini untuk memperoleh data yang berhubungan dengan masalah yang diteliti yaitu sebagai berikut:

1. Kajian pustaka dan laporan terkait serta bahan-bahan yang tertulis yang ada kaitannya dengan masalah yang diteliti.

2. Studi lapangan, yaitu pengumpulan data yang langsung terjun kelapangan dengan cara sebagai berikut:

a. Kuisioner, yang merupakan teknik pengumpulan data yang dilakukan dengan cara memberi seperangkat pernyataan tertulis untuk dijawabnya. Bentuk kuisionernya adalah kuisioner terstruktur, pernyataan yang dibuat sedemikian rupa sehingga responden dibatasi dalam memberi jawaban pada beberapa alternatif saja ataupun kepada satu jawaban saja (sugiyono : 2014).

b. Observasi, adalah cara pengambilan data dengan pengamatan tanpa ada alat standar lain untuk keperluan tersebut.

c. Dokumentasi, adalah teknik pengumpulan data sekunder yang dilakukan dengan mencatat dokumen yang berhubungan dengan variabel penelitian.

d. Skala pengukuran penelitian ini yang digunakan adalah likert. Pengukuran untuk variable independent dan dependent menggunakan teknik scoring untuk memberikan nilai pada setiap alternative jawaban sehingga data dapat dihitung.

\section{Sampel dan Populasi}

Populasi dalam penelitian ini yaitu karyawan CV. Mitra Tunas Mandiri (MTM) Bandar Lampung. Semua karyawan tersebut peneliti menjadikanya sampel dengan menggunakan metode sampling jenuh dimana semua populasi dijadikan sampel. 


\section{Metode Analisis Data}

Cara menganalisis pengaruh disiplin kerja dan punishment terhadap produktivitas kerja karyawan CV MITRA TUNAS MANDIRI (MTM) lampung dengan menggunakan validitas. Validitas merupakan suatu ukuran yang menunjukan tingka kevalidan suaru instrument. Untuk mengetahui validitas kuisioner digunakan rumus korelasi product moment (Suharismi Arikunto : 2006) sebagai berikut :

$$
\mathrm{r}_{\mathrm{xy}} \frac{\mathrm{n} \sum_{1=1}^{\mathrm{n}} \mathrm{X}_{\mathrm{i}} \mathrm{Y}_{\mathrm{i}}-\sum_{1=1}^{\mathrm{n}} \mathrm{X}_{\mathrm{i}} \cdot \sum_{1=1}^{\mathrm{n}} \mathrm{X}_{\mathrm{i}}}{\sqrt{\left[\mathrm{n} \sum_{1=1}^{\mathrm{n}} \mathrm{X}_{1}^{2}-\left(\sum_{1=1}^{\mathrm{n}} \mathrm{X}_{\mathrm{i}}\right)^{2}\right]\left[\mathrm{n} \sum_{1=1}^{\mathrm{n}} \mathrm{Y}_{1}^{2}-\left(\sum_{1=1}^{\mathrm{n}} \mathrm{Y}_{\mathrm{i}}^{2}\right)^{2}\right]}}
$$

Kriteria pengambilan keputusan sebagai berikut :

a. Jika $r$ hitung $>\mathrm{r}$ tabel maka kuisioner dinyatakan valid.

b. Jika $\mathrm{r}$ hitung < $\mathrm{r}$ tabel maka kuisioner dinyatakn tidak valid.

Pada realibilitas alat ukur menunjukan pada kita tentang sifat suatu alat ukur dalam pengertian apakah suatu alat ukur cukup akurat, stabil atau konsisten dalam mengukur apa yang ingin kita ukur (Nazir : 2015). Uji realibilitas yang digunakan pada penelitian ini adalah dengan menggunakan rumus alpha cronbach. Menurut (Arikunto : 2006), rumus alpha cronbach adalah sebagai berikut :

$$
r_{11}=\left[\frac{k}{k-1}\right]\left[1-\frac{\sum s_{i}^{2}}{s_{t}^{2}}\right]
$$

Keterangan :

$\begin{array}{ll}\mathrm{r} 11 & : \text { Realibilitas instrument } \\ \mathrm{k} & : \text { banyaknya butir soal } \\ s_{t}^{2} & : \text { Varians total } \\ \sum_{i}^{2} s_{i}^{2} & : \text { Jumlah seluruh varians } \\ \text { masing - masng soal }\end{array}$

\footnotetext{
Dengan kriteria pengambilan keputusan sebagai berikut :
}

a. Jika nilai alpha cronbach secara keseluruhan > alpha cronbach if item deleted, maka dinyatakan realibel.

b. Jika nilai alpha cronbach secara keseluruhan < alpha cronbach if item delted, maka dinyatakan tidak realibel.

\section{HASIL DAN PEMBAHASAN}

\section{Uji Validitas Data}

Sebelum dilakukan pengolahan data maka seluruh jawaban yang diberikan oleh responden diuji denga uji validitas yang diuji cobakan pada responden. Dengan penelitian ini, uji validitas untuk menghitung data yang dihitung.

\begin{tabular}{|c|c|c|c|c|c|}
\hline Pernyataan & $\mathrm{r}_{\text {hitung }}$ & $\mathrm{r}_{\text {tabel }}$ & Kon & & Kesimpulan \\
\hline Butir 1 & 0,751 & 0,361 & $\begin{array}{l}\mathrm{r}_{\text {hitun }} \\
\mathrm{r}_{\text {tabel }}\end{array}$ & $>$ & Valid \\
\hline Butir 2 & 0,681 & 0,361 & $\begin{array}{l}\mathrm{r}_{\text {hitun }} \\
\mathrm{r}_{\text {tabel }}\end{array}$ & $>$ & Valid \\
\hline Butir 3 & 0,492 & 0,361 & $\begin{array}{l}\mathrm{r}_{\text {hitun }} \\
\mathrm{r}_{\text {tabel }}\end{array}$ & $>$ & Valid \\
\hline Butir 4 & 0,633 & 0,361 & $\begin{array}{l}\mathrm{r}_{\text {hitun }} \\
\mathrm{r}_{\text {tabel }}\end{array}$ & $>$ & Valid \\
\hline Butir 5 & 0,751 & 0,361 & $\begin{array}{l}\mathrm{r}_{\text {hitun }} \\
\mathrm{r}_{\text {tabel }}\end{array}$ & $>$ & Valid \\
\hline Butir 6 & 0,681 & 0,361 & $\begin{array}{l}\mathrm{r}_{\text {hitun }} \\
\mathrm{r}_{\text {tabel }}\end{array}$ & $>$ & Valid \\
\hline Butir 7 & 0,569 & 0,361 & $\begin{array}{l}\mathrm{r}_{\text {hitun }} \\
\mathrm{r}_{\text {tabel }}\end{array}$ & $>$ & Valid \\
\hline Butir 8 & 0,606 & 0,361 & $\begin{array}{l}\mathrm{r}_{\text {hitun }} \\
\mathrm{r}_{\text {tabel }}\end{array}$ & & Valid \\
\hline
\end{tabular}

Tabel 1. Hasil Uji Validitas Disiplin Kerja(X1)

Berdasarkan tabel diatas hasil uji validitas variabel disiplin kerja X1 dengan menapilkan seluruh item pernyataan yag bersagkutan mengenai disiplin kerja. Hasil yang didaptkan yaitu nilai $\mathrm{r}_{\text {hitung }}$ lebih besar dari $\mathrm{r}_{\text {tabel }}$ 0.361, dinamakan nilai $\mathrm{r}_{\text {hitung }}$ paling tinggi yaitu 0,751 dan paling rendah 0,492. Dengan demikian seluruh item disiplin kerja dinyatakan valid.

Tabel 2. Hasil Uji Validitas Punishment (X2)

\begin{tabular}{|l|l|l|l|l|}
\hline Pernyataan & $\mathrm{r}_{\text {hitung }}$ & $\mathrm{r}_{\text {tabel }}$ & Kondisi & Kesimpulan \\
\hline Butir 1 & 0,573 & 0,361 & $\begin{array}{l}\mathrm{r}_{\text {hitung }}> \\
\mathrm{r}_{\text {tabel }}\end{array}$ & Valid \\
\hline Butir 2 & 0,629 & 0,361 & $\begin{array}{l}\mathrm{r}_{\text {hitung }}> \\
\mathrm{r}_{\text {tabel }}\end{array}$ & Valid \\
\hline Butir 3 & 0,585 & 0,361 & $\mathrm{r}_{\text {hitung }}>$ & Valid \\
\hline
\end{tabular}




\begin{tabular}{|c|c|c|c|c|}
\hline & & & $\mathrm{r}_{\mathrm{tabel}}$ & \\
\hline Butir 4 & 0,579 & 0,361 & $\begin{array}{l}\mathrm{r}_{\text {hitung }} \\
\mathrm{r}_{\text {tabel }}\end{array}$ & Valid \\
\hline Butir 5 & 0,656 & 0,361 & $\begin{array}{l}\mathrm{r}_{\text {hitung }} \\
\mathrm{r}_{\text {tabel }}\end{array}$ & Valid \\
\hline Butir 6 & 0,478 & 0,361 & $\begin{array}{l}\mathrm{r}_{\text {hitung }} \\
\mathrm{r}_{\text {tabel }} \\
\end{array}$ & Valid \\
\hline
\end{tabular}

Berdasarkan tabel diatas hasil uji validitas variabel Punishment X2 dengan menapilkan seluruh item pernyataan yag bersagkutan mengenai Punishment. Hasil yang didaptkan yaitu nilai $\mathrm{r}_{\text {hitung }}$ lebih besar dari $\mathrm{r}_{\text {tabel }}$ 0.361, dinamakan nilai $\mathrm{r}_{\text {hitung }}$ paling tinggi yaitu 0,858 dan paling rendah 0,478 . Dengan demikian seluruh item Punishment dinyatakan valid.

Tabel 3. Hasil Uji Validitas Produktivitas Kerja (Y)

\begin{tabular}{|l|l|l|l|l|}
\hline Pernyataan & $\mathrm{r}_{\text {hitung }}$ & $\mathrm{r}_{\text {tabel }}$ & Kondisi & Kesimpulan \\
\hline Butir 1 & 0,627 & 0,361 & $\begin{array}{l}\mathrm{r}_{\text {hitung }} \\
\mathrm{r}_{\text {tabel }}\end{array}$ & Valid \\
\hline Butir 2 & 0,575 & 0,361 & $\begin{array}{l}\mathrm{r}_{\text {hitung }} \\
\mathrm{r}_{\text {tabel }}\end{array}$ & Valid \\
\hline Butir 3 & 0,735 & 0,361 & $\begin{array}{l}\mathrm{r}_{\text {hitung }} \\
\mathrm{r}_{\text {tabel }}\end{array}$ & Valid \\
\hline Butir 4 & 0,721 & 0,361 & $\begin{array}{l}\mathrm{r}_{\text {hitung }} \\
\mathrm{r}_{\text {tabel }}\end{array} \quad$ & Valid \\
\hline Butir 5 & 0,862 & 0,361 & $\begin{array}{l}\mathrm{r}_{\text {hitung }} \\
\mathrm{r}_{\text {tabel }}\end{array} \quad$ Valid \\
\hline Butir 6 & 0,772 & 0,361 & $\begin{array}{l}\mathrm{r}_{\text {hitung }} \\
\mathrm{r}_{\text {tabel }}\end{array}$ & Valid \\
\hline
\end{tabular}

Berdasarkan tabel diatas hasil uji validitas variabel Produktivitas Kerja Y dengan menapilkan seluruh item pernyataan yag bersagkutan mengenai Produktivitas Kerja. Hasil yang didaptkan yaitu nilai $\mathrm{r}_{\text {hitung }}$ lebih besar dari $\mathrm{r}_{\text {tabel }} 0.361$, dinamakan nilai $r_{\text {hitung }}$ paling tinggi yaitu 0,862 dan paling rendah 0,575. Dengan demikian seluruh item Produktivitas Kerja dinyatakan valid.

\section{Uji Realibilitas}

Setelah uji validitas maka penguji kemudian melakukan uji realibilitas terhadap masing-masing instrumen variabel $\mathrm{X} 1$, variabel $\mathrm{X} 2$, dan instrumen variabel $\mathrm{Y}$ menggunaka rumus Alpha Cronbach dengan batuan program SPSS 22 .

\begin{tabular}{|l|l|l|l|}
\hline Variabel & $\begin{array}{l}\text { Koefisien } \\
\text { Cronbachs } \\
\text { Alpha }\end{array}$ & $\begin{array}{l}\text { Koefisien } \\
\mathbf{R}\end{array}$ & Kesimpulan \\
\hline Disiplin Kerja & 0,799 & $\begin{array}{l}0,6000- \\
0,7999\end{array}$ & Tinggi \\
\hline Punishment & 0,633 & $\begin{array}{l}0,6000 \\
-0,7999\end{array}$ & Tinggi \\
\hline $\begin{array}{l}\text { Produktivitas } \\
\text { Kerja }\end{array}$ & 0,804 & $\begin{array}{l}0,8000- \\
1,000\end{array}$ & $\begin{array}{l}\text { Sangat } \\
\text { Tinggi }\end{array}$ \\
\hline
\end{tabular}

Berdasarkan hasil uji reliabilitas tabel diatas nilai Cronbachs Alpha sebesar 0,799 untuk disiplin kerja (X1) dengan tingkat tinggi, 0,633 untuk variabel Punishment (X2) dengan tingkat reliabel tinggi dan 0,804 untuk variabel Produktivitas Kerja (Y) yang diartikan tingkat reliabel sangat tinggi.

\section{KESIMPULAN DAN SARAN}

\section{Kesimpulan}

Berdasarkan hasil analisis data dan pengujian hipotesis yag telah dilakukan, maka kesimpulan dalam penelitian ini adalah :

1) Disiplin Kerja berepengaruh signifikan terhadap Produktivitas Kerja Pegawai CV Mitra Tunas Mandiri Bandar Lampung karena, koefisien regresi Displin Kerja sebesar 0,513. Disiplin Kerja adalah suatu alat yang digunakan manajer untuk mengubah suatu perilaku serta sebagai suatu upaya untuk meningkatka kesadaran dan kesediaan seseorag menaati semua peraturan serta norma - norma sosial yang berlaku.

2) Punishment berpengaruh signifikan terhadap Produktivitas Kerja Pegawai di CV Mitra Tunas Mandiri Bandar Lampung karena, koefisien regresi Punishment sebesar 0,078. Punishment merupakan ancaman hukuman yag bertujuan untuk memperbaiki pegawai pelanggar, memelihara peraturan yag berlaku dan memberikan pelajaran kepada pelanggar. 
3) Disiplin Kerja dan Punishment signifikan terhadap Produktivitas Kerja Pegawai CV Mitra Tunas Mandiri Bandar Lampung karena, koefisien regresi Displin Kerja sebesar 0,513 dan Punishment sebesar 0,078. Hal ini berarti bahwa pegawai pada CV Mitra Tunas Mandiri sudah memiliki disiplin kerja yang cukup dalam bekerja dan Punishment dengan penerapan yang sesuia dengan ebijakan perusahaan.

\section{Saran}

1) Disiplin Kerjapada CV Mitra Tunas Mandiri Bandar Lampung harus diperbaiki karena kedisiplinan yang dilakukan masih kurang sehingga dapat menjadi masalah dalam penyelesaian pekerjaan para pegawai. Punishment yang diberikan harus benar-benar diterapkan karena dengan adanya hukuman yang tegas maka pegawai tida akan mengulangi kesalahannya.

2) Dalam penelitian ini peneliti menggunakan teori - teori yang berkaitan dengan Displin Kerja, Punishment dan Teori Produktivitas Kerja. Demi kemajuan Ilmu Pengetahuan diharpak bagi peneliti selanjutnya dapat menggunaka indikator lainnya yang berbeda dengan penelitian yang sudah ada.

\section{DAFTAR PUSTAKA}

S.P,Hasibuan, Malayu. 2013. Manajemen Sumber Daya Manusia. Jakarta: PT Bumi Aksara

Mathis Robert, Jackson John. 2002. Manajemen Sumber Daya Manusia. Jakarta : Salemba empat
Danang, Sunyoto. 2012. Manajemen Sumber Daya Manusia. Jakarta: PT Buku Seru.

Gouzali Saydam, (2000), Manajemen Sumber Daya Manusia (Human Resource) Suatu Pendekatan Mikro. Jakarta: Djanbatan.

Ngalim Purwanto. 2007. Psikologi Pendidikan. Bandung: PT Remaja Rosdakarya.

Martoyo, Susilo. 2000. Manajemen Sumber Daya Manusia. Jogjakarta: PT BPFE - Yogyakarta

Hasibuan, Malayu S. P. 2006, Manajemen Sumber Daya Manusia, Edisi Revisi : Jakarta. Bumi Aksara

Hasibuan, Malayu S. P. 2006, Manajemen Sumber Daya Manusia, Edisi Revisi : Jakarta. Bumi Aksara

Edwin B. Flippo. 1996. Manajemen Personalia Jilid I. Alih bahasa oleh Moh Masud, SH.,MA. Jakarta: Erlangga.

Flippo, Edwin B. 2014. Manajemen Sumber Daya Manusia. Jakarta: Penerbit Bina Aksara.

George, D and Mallery, P. 2013. SPSS/PC Step by Step a Simple Guide and Reference. Belenot: Wods Worbb Publishing Company.

Greenberg, J and Baron, R. 2014. Behavior in Organizations. New Jersey: Prentice Hall International, Inc. 